\title{
INTEGRAL OPERATORS WITH TWO VARIABLE INTEGRATION LIMITS ON THE CONE OF MONOTONE FUNCTIONS
}

\author{
Aigerim Kalybay, Ryskul Oinarov and Ainur TEMirkHanova
}

\begin{abstract}
Weighted inequalities for the Hardy-Steklov operators with variable integration limits on the cone of monotone functions have been investigated with success. The similar problem for operators with kernels has remained unsolved up to now. In this paper we find characterizations for integral operators with a wide class of kernels.
\end{abstract}

\section{Mathematics subject classification (2010): 26D10, 47B38.}

Keywords and phrases: Integral operator with variable integration limits, Hardy-Steklov operator, weighted inequality, non-increasing function, non-decreasing function.

\section{REFERENCES}

[1] L. S. Arendarenko, R. Oinarov and L.-E. Persson, Some new Hardy-type integral inequalities on cones of monotone functions, Advances in Harmonic Analysis and Operator Theory, edited by Alexandre Almeida, Luis Filipe Castro, Frank-Olme Speck; Springer, Basel, 2013, 77-89.

[2] E. N. Batuev and V. D. Stepanov, On weighted inequalities of Hardy type, Siberian Math. J. 30, (1989), 8-16.

[3] T. Chen And G. Sinnamon, Generalized Hardy operators and normalizing measures, J. Inequal. and Appl. 7, 6 (2002), 829-866.

[4] A. GogatishVili and J. LANG, The generalized Hardy operator with kernel and variable integral limits in Banach function spaces, J. Inequal. Appl. 4, 1 (1999), 1-16.

[5] A. GogatishVili and V. D. Stepanov, Reduction theorems for weighted integral inequalities on the cone of monotone functions, Russian Math. Surveys 68, 4 (2013), 597-664.

[6] H. P. Heinig And G. Sinnamon, Mapping properties of integral overaging operators, Stud. Math. 129, (1998), 157-177.

[7] H. P. Heinig AND V. D. Stepanov, Weighted Hardy inequalities for increasing functions, Canad. J. Math. 45, 1 (1993), 104-116.

[8] A. Kufner, L. Maligranda And L.-E. Persson, The Hardy inequality. About its history and some related results, Vydavatelský servis, Pilsen, 2007.

[9] A. Kufner And L.-E. Persson, Weighted inequalities of Hardy type, World Scientific, New Jersey/London/Singapore/Hong Kong, 2003.

[10] R. OINAROV, Boundedness and compactness in weighted Lebesgue spaces of integral operators with variable integration limits, Siberian Math. J. 52, 6 (2011), 1042-1055.

[11] R. Oinarov, Boundedness of integral operators from weighted Sobolev space to weighted Lebesgue space, Complex Variables and Elliptic Equations 56, 10-11 (2011), 1021-1038.

[12] R. Oinarov, Boundedness of integral operators in weighted Sobolev spaces, Izvestiya: Mathematics 78, 4 (2014), 836-853.

[13] D. V. Prokhorov, V. D. Stepanov and E. P. Ushakova, Hardy-Steklov integral operators, Part 1. Proc. Steklov Inst. Math. 300, (Suppl. 2) (2018), 1-111; translated from Sovrem. Probl. Mat. 22, Steklov Math. Institute of RAS, Moscow, 2016.

[14] E. SAWYER, Boundedness of classical operators on classical Lorentz spaces, Stud. Math. 96, 2 (1990), $145-158$. 
[15] G. Sinnamon, Hardy's Inequality and Monotonicity, Proceedings Function Spaces, Differential Operators and Nonlinear Analysis, Mathematical Institute of the Academy of Sciences of the Czech Republic, Prague, 2005, 292-310.

[16] V. D. StePAnOV, Integral operators on the cone of monotone functions, J. London Math. Soc. 48, 3 (1993), 465-487.

[17] V. D. StePAnOv, The weighted Hardy's inequality for nonincreasing functions, Trans. Amer. Math. Soc. 338, 1 (1993), 173-186.

[18] V. D. Stepanov and E. P. Ushakova, On integral operators with variable limits of integration, Proc. Steklov Inst. Math. 232, (2001), 290-309.

[19] V. D. Stepanov and E. P. UshaKova, On the geometric mean operator with variable limits of integration, Proc. Steklov Inst. Math. 260, (2008), 254-278.

[20] V. D. Stepanov And E. P. Ushakova, Kernel operators with variable intervals of integration in Lebesgue spaces and applications, Math. Inequal. Appl. 13, 3 (2010), 449-510.

[21] V. D. StePANOV AND E. P. UshaKova, Hardy operator with variable limits on monotone functions, J. Funct. Spaces Appl. 1, 1 (2003), 1-15.

[22] E. P. Ushakova, Alternative boundedness characteristics for the Hardy-Steklov operator, Eurasian Math. J. 8, 2 (2017), 74-96.

[23] E. P. Ushakova, On boundedness and compactness of a certain class of kernel operators, J. Funct. Spaces Appl. 9, (2011), 67-107. 